\title{
Clinico-demographic Profile and outcome of acute poisoning among children- a single Centre observational study.
}

\author{
Susheela $C^{1}$, Manjunatha Babu $\mathbf{R}^{2}$, Yellappa Gowda ${ }^{3}$ \\ ${ }^{1}$ Dr. Susheela C, Professor \& HOD, Department of Paediatrics, Vydehi Institute Medical Sciences and Research Centre, \\ Bengaluru, Karnataka, India. ${ }^{2}$ Dr. Manjunatha Babu R, Associate Professor, Department of Paediatrics, Vydehi Institute \\ Medical Sciences and Research Centre, Bengaluru, Karnataka, India. ${ }^{3}$ Dr. Yellappa Gowda, Assistant Professor, \\ Department of Paediatrics, SDUMC, Tamaka, Kolar, Karnataka, India.
}

Address for Correspondence: Dr. Manjunatha Babu R, Associate Professor, Department of Paediatrics, Vydehi Institute of Medical Sciences and Research Centre, Whitefield, Bengaluru. Email id: manjunath.babu9@gmail.com

\begin{abstract}
Background: Poisoning in children is a global problem and no part of the world is exempt from this calamity. It is one of the commonest preventable emergencies encountered in pediatric practice. Methods: This prospective observational study was done from November 2015 to October 2016. Patients admitted with clear history of poisoning/bite were enrolled during the study period and were carefully monitored for the course, complications and outcome. Patient details like age, sex, socioeconomic status, symptoms, signs, type of poison/bite, mode, reason for poisoning, any prior treatment received and reasons for delayed treatment if any were collected during the hospital stay. Results: A total of 119 cases of poisoning/bite were enrolled. Organophosphorus (OP) poisoning outnumbered the poisoning agents and Snake bite out numbered in Bites and Stings. Majority of cases were in the age group of 13-18 years. Male to female ratio $1.2: 1$. Rural to urban incidence of poisoning was 2.7:1. Highest incidence was observed in children from lower socioeconomic nuclear families and parents with lower educational status. Accidental poisoning outnumbered the suicidal poisoning. Vomiting, Pain, bleeding, Swelling, cough, pain abdomen, drowsiness, nausea, diarrhea, breathlessness, excessive salivation, sweating were observed in majority of the cases. Average hospital stay was 3.5 days ( 2 to 7 days). There was no mortality in this study. Conclusions: Parental health education will decreases the occurrence of childhood poisoning. Along with the parents and teachers, media also should take active steps to educate the rural population about the preventive measures from bite, stings and handling of poisonous agents.
\end{abstract}

Keywords: Children, Clinical profile, Poisoning, Snake bite.

\section{Introduction}

Poisoning in children is a global problem and no part of the world is exempt from this calamity. It is one of the commonest preventable emergencies encountered in pediatric practice [1]. The cause and type of poisoning vary in different parts of the world, depending on the accessibility of poison to children, which depends upon factors such as demography, socio-economic status, education, local beliefs and customs [2]. Though the reported incidence of childhood poisoning varies from 0.3 to 7.6 percent in various Indian hospitals, the incidence appears to be much higher, since there is no community based study from India [3]. The incidence also tends to be higher among children from lower

Manuscript received: $15^{\text {th }}$ November 2016

Reviewed: $26^{\text {th }}$ November 2016

Author Corrected; $10^{\text {th }}$ December 2016

Accepted for Publication: $22^{\text {nd }}$ December 2016 socio-economic status, where the storage facilities may be inadequate for house hold products as well as for medical agents and even for known toxic substances, such as pesticides [3]. Thus environmental conditions including those related to housing are likely to be main contributing factors to childhood poisoning [2]. Studies performed in developed countries consider family stress, personality and behavioral problem of children, related to childhood poisoning [4].

Mortality in childhood poisoning is accounts for $0.03 \%$ in infants, $0.16 \%$ in $1-4$ years of age group and $0.37 \%$ in 5-14 years of age group respectively [3]. In view of the paucity of proper report from our country and the possible regional difference, it was considered worthwhile to take up the present study to study the 
clinico-demographic profile and analyze the outcome of treatment among the cases admitted to pediatric wards.

\section{Material and Methods}

This prospective observational study was undertaken in the department of Pediatrics at a tertiary care medical teaching hospital over a period of 1 year. Patients admitted with clear history of poisoning/bite were enrolled during the study period and were carefully monitored for the course, complications and their outcome. Children aged 1 to 18 years with history of acute poisoning, Snake bite, Scorpion sting and insect bites were included. Cases with signs and symptoms of coagulopathy, haemotoxicity and myotoxicity with no history of poisoning/bite and unknown poisoning were excluded from the study. Patient details like age, sex, socioeconomic status, symptoms, signs, type of poison/bite, mode, reason for poisoning, any prior treatment received, reasons for delayed treatment if any were collected during the hospital stay and patients were managed as per standard guidelines. Final outcome of the treatment was documented.

\section{Results}

The total number of cases in Pediatric wards during study period were 3960, out of which 119 were of poisoning/bite cases which accounts for 3\%. Organophosphorus poisoning (OP) outnumbered other poisonings and Snake bite outnumbered in bites and stings. Maximum number of cases were in the age group of 13-18 years, followed by the age group of 1-5 years. Male patients outnumbered the female patients with incidence of male to female ratio 1.2: 1. Most of the cases were from the nearby villages. Ratio between rural and urban incidence of poisoning was 2.7. Highest incidence of poisoning was observed in children of parents with lower educational status. Noted to have more poisonings in the nuclear family than the joint families. Majority of poisonings cases were from lower economic status [Table 1].

Table-1: Socio-demographic profile of acute poisoning.

\begin{tabular}{|c|c|c|}
\hline Variables & Number of cases & Percentage (\%) \\
\hline Gender & & \\
Male & 66 & 55.6 \\
Female & 53 & 44.4 \\
\hline Age (Years) & & \\
$1-5$ & 34 & 28.7 \\
$6-12$ & 19 & 15.9 \\
$13-18$ & 66 & 55.4 \\
\hline Socioeconomic Status & 0 & 0 \\
Class - I & 13 & 10.9 \\
Class II & 29 & 24.4 \\
Class - III & 77 & 64.7 \\
Class IV and V & 32 & 26.8 \\
\hline Demography & 87 & 73.2 \\
Urban & & \\
Rural & 47 & 39.5 \\
\hline IIliterate & 46 & 38.5 \\
\hline Primary and Middle School & 17 & 14.5 \\
Higher Secondary School & 9 & 7.5 \\
College and above & 82 & 68.9 \\
\hline Type of family & 37 & 31.1 \\
Nuclear family & & \\
Joint family & & \\
\hline
\end{tabular}

Accidental poisoning outnumbered the suicidal poisoning. Maximum cases were observed in the time interval of 6 pm to $11.59 \mathrm{pm}$. Number of Snake Bite cases outnumbered during the evening hours and O.P. poisoning cases outnumbered in an interval of $12 \mathrm{pm}$ to $5.59 \mathrm{pm}$ in the afternoon hours [Table.2]. 
Table-2: Characteristics of Poisoning in children.

\begin{tabular}{|c|c|c|}
\hline Variables & Number of cases & Percentage (\%) \\
\hline $\begin{array}{c}\text { Types of poisoning } \\
\text { Organophosphorus } \\
\text { Kerosene } \\
\text { Snake bite } \\
\text { Scorpion Sting } \\
\text { Corrosives } \\
\text { Rodenticides } \\
\end{array}$ & $\begin{array}{c}47 \\
18 \\
42 \\
4 \\
3 \\
5\end{array}$ & $\begin{array}{c}39.5 \\
15.1 \\
35.3 \\
3.4 \\
2.5 \\
4.2 \\
\end{array}$ \\
\hline $\begin{array}{c}\text { Mode of poisoning } \\
\text { Accidental } \\
\text { Suicidal } \\
\text { Homicidal } \\
\end{array}$ & $\begin{array}{c}75 \\
44 \\
0\end{array}$ & $\begin{array}{c}63 \\
37 \\
0\end{array}$ \\
\hline $\begin{array}{c}\text { Approximate time of poisoning(hrs) } \\
6 \mathrm{am}-12 \mathrm{pm} \\
12 \mathrm{pm}-6 \mathrm{pm} \\
6 \mathrm{pm}-12 \mathrm{am} \\
\end{array}$ & $\begin{array}{c}4 \\
57 \\
58 \\
\end{array}$ & $\begin{array}{c}3.36 \\
47.90 \\
48.74\end{array}$ \\
\hline $\begin{array}{c}\text { First Aid } \\
\text { Received } \\
\text { Not received } \\
\end{array}$ & $\begin{array}{l}83 \\
36 \\
\end{array}$ & $\begin{array}{l}70 \\
30 \\
\end{array}$ \\
\hline 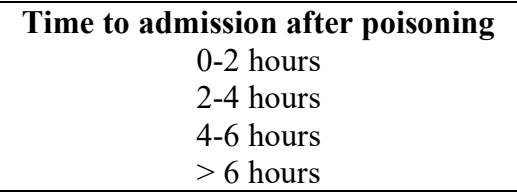 & $\begin{array}{l}49 \\
53 \\
10 \\
7\end{array}$ & $\begin{array}{c}41.1 \\
44.6 \\
8.5 \\
5.8\end{array}$ \\
\hline $\begin{array}{c}\text { Duration of hospital stay (Days) } \\
1-2 \\
3-7 \\
>7\end{array}$ & $\begin{array}{l}52 \\
53 \\
14\end{array}$ & $\begin{array}{l}43.6 \\
44.6 \\
11.8 \\
\end{array}$ \\
\hline $\begin{array}{l}\text { Outcome } \\
\text { Recovered } \\
\text { Death }\end{array}$ & $\begin{array}{c}119 \\
0\end{array}$ & $\begin{array}{c}100 \\
0\end{array}$ \\
\hline
\end{tabular}

Most of the Poisoning cases occurred in the month of May accounting for $21 \%$ of the cases [Figure 1]. $70 \%$ of the cases had received first aid before admission to the hospital. Vomiting, Pain, bleeding \& Swelling at the bite site, cough, pain abdomen, drowsiness, nausea, diarrhea, breathlessness, excessive salivation, sweating were observed in majority of the cases. Odour of poisoning agent, miosis, excessive salivation, defecation, altered sensorium, abnormal lung findings were observed in other poisoning incidences [Table 3].

Table-3: Clinical Profile of poisoning.

\begin{tabular}{|c|c|c|c|c|c|}
\hline Symptoms & Number & Percentage \% & Signs & Number & $\begin{array}{c}\text { Percentage } \\
\text { \% }\end{array}$ \\
\hline Vomiting & 85 & 71.5 & Odour of poison & 66 & 55.5 \\
\hline $\begin{array}{c}\text { Pain and swelling at } \\
\text { bite sites }\end{array}$ & 39 & 32.8 & Fang Marks \& bite site & 44 & 36.9 \\
\hline Cough & 38 & 31.9 & Swelling & 44 & 36.9 \\
\hline Pain Abdomen & 38 & 31.9 & Local reaction at bite sites & 39 & 32.7 \\
\hline Drowsiness & 32 & 26.8 & Abnormal lung findings & 38 & 31.9 \\
\hline Nausea & 30 & 25.3 & Tachycardia & 36 & 30.3 \\
\hline $\begin{array}{c}\text { Bleeding from the } \\
\text { bite site }\end{array}$ & 30 & 25.3 & Cellulitis & 36 & 30.3 \\
\hline Diarrhea & 22 & 18.5 & Tachypnea & 28 & 23.5 \\
\hline Breathlessness & 22 & 18.5 & Defecation & 24 & 20.1 \\
\hline Excessive salivation & 22 & 18.5 & Miosis & 24 & 20.1 \\
\hline Sweating & 20 & 16.8 & Excessive salivation & 22 & 18.5 \\
\hline
\end{tabular}

Vomiting and odour were most common presenting symptom and sign respectively 


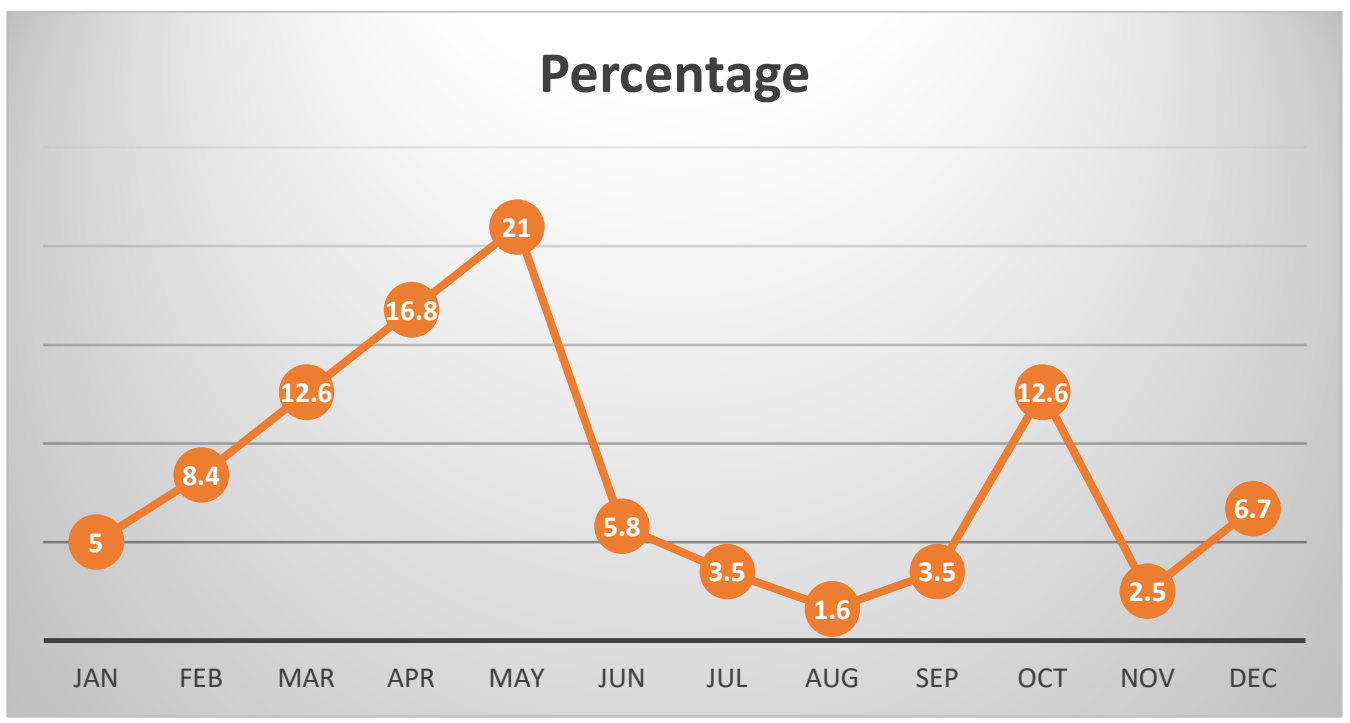

Figure-1: Monthly incidence of Poisoning

Most cases (53\%) were admitted within 4 hours of consumption/bite. Average duration of stay in the hospital was 3.5 days. Duration of hospital stay increased as delay in the time interval of admission to the hospital from the time of consumption of poison. There was no mortality in this study.

\section{Discussion}

The incidence of child hood poisoning in Indian studies $[5,6,7]$ varies between $0.3 \%$ to $7.6 \%$. The occurrence of poisoning in the present study is similar to the study of Dutta AK [3]. Incidence of childhood poisoning was more $(55.4 \%)$ in the age group of 13-18 years. Males were outnumbered females with a ratio of 1.2:1 in the present study, which were similar to other studies [3, 7,8]. Accidental poisonings outnumbered the suicidal poisonings in the present study $63.1 \%$, which were similar to the other Indian [5,7] and international studies [8].

Majority of the cases (58.8\%) were reported during summer season similar to other Indian studies $[9,10]$ which noticed $41.7 \%$ and $37.3 \%$. Winter season witnessed least number of cases in both Indian and present studies. In the present study rural cases outnumbered the urban cases, which was inconsistent with other international [8] and Indian studies [6].

However it agrees with the study by Ramesh S [11], since our center caters to more number of rural population. $89.1 \%$ of cases were from lower socio economic status similar to another study [6]. Singh S [2] reported $98.6 \%$ of cases from both middle and lower socio economic group. Possible factors for incidence of poisoning in lower and middle socio economic status were illiteracy, neglect of children, lack of awareness regarding the poisoning agents, lack of health education and nuclear families. It is pertinent to note that negligible cases were noted from the upper socio economic class in all the studies. In the present study more number of cases were due to Organ phosphorous poisoning followed by poisoning due to Snake bite, Kerosene poisoning, Aluminum phosphide, Scorpion sting and Corrosive acid.

Dutta AK [3] in their study on childhood poisoning have reported that various regions in the country showed variation in types of poisoning which could be attributed to different geographical and socio economic background. Present study noticed more (39.5\%) OP poisonings than other Indian [2] and western [8] studies. In our study OP poisoning makes the chunk of poisoning case followed by Snake bite this can be attributed to the rural population working in fields is a access to pesticides, insecticide and increased exposure to animal bite and stings. Snake bite constituting $35.3 \%$ of total poisoning cases similar to other Indian study [3]. Kerosene poisoning constituting $15.1 \%$ of total poisoning cases which was similar to the study of Dutta AK [3].

Majority of the cases $(85.7 \%)$ were admitted to hospital within 4 hours of poisoning,which was similar to other comparative study[8]. Majority of the cases stayed for 
3 -7 days and few cases stayed beyond 7 days. The duration of hospital stay was more in our study when compared to other studies $[6,12]$

We have noticed the delay in seeking medical treatment has resulted in increased stay in the hospital. No mortality was reported but high morbidity like increased duration of stay in the hospital was observed. Some Indian studies [3,11] have reported the low mortality rate of $0.6 \%-0.9 \%$. Ganga $\mathrm{N}$ [13] and Singh S [2] have reported high mortality rate of $3.9 \%$ \& $12.9 \%$ respectively.

\section{Conclusions}

Parental health education will decrease the occurrence of childhood poisoning and there is a need to strengthen the preventive measures. The young children should be kept under strict supervision and constant vigilance. Along with the parents and teachers, media also should take active steps to educate the rural population about the preventive measures from bite, stings and handling of poisonous agents.

\section{Funding: Nil, Conflict of interest: Nil \\ Permission from IRB: Yes}

\section{Bibliography}

1. Singh M, Hessam MY, Azamy S, Arya LS. Spectrum of poisonings among children in Afghanistan. Indian $\mathrm{J}$ Pediatr. 1984; 51: 313-6.

2. Singh S, Sood NK, Walia BNS, Kumar L. Changing pattern of childhood poisoning: Experience of a large north Indian Hospital. Indian Pediatr. 1995; 32: 332-5.
3. Dutta AK, Seth A, Goyal PK, et al. Poisoning in children: Indian scenario. Indian J Pediatr. 1998 MayJun;65(3):365-70.

4. Surpure J, Lall SB. Accidental pediatric poisoning A preventable medical emergency. Indian $\mathrm{J}$ Pediatr. $1998 ; 65: 363-4$

5. Singhal, PK, Kumar H, Rastogi V,et al. Accidental poisoning. Indian Pediatr.1988;25: 350-3.

6. Tak SK, Bandari B, Jain AM, et al. Accidental poisoning in children. Indian pediatr. 1979;30: 765-768.

7. Niayaz AB, Ahmed K, Sethi AS. Poisoning in children. Indian Pediatr.1991;28:521-4.

8. Aqeel M, Munir A,Khan A. Pak $J$ Med Sci 2009; 25(3): 479-3.

9. Khadgawat R, Garg P, Bansal P. Accidental poisoning. Indian Pediatr.1994; 31:1555-7.

10. Kumar V. Accidental poisoning in South West Maharashtra. Indian Pediatr.1991;28: 731-5.

11. Ramesh S, Srikanth S, Parvathy VR. Poisoning in children. Indian J Pediatr.1986; 54: 769-73.

12. Gupta P, Singh KP, Murali MV. Kerosene oil poisoning - A childhood menace. Indian Pediatr 1992; 29: $979-83$.

13. Ganga N, Rajarajeshwari G. Poisoning in children. Indian Pediatr.2001; 38:208.

\section{How to cite this article?}

Susheela C, Manjunatha Babu R, Yellappa Gowda. Clinico-demographic Profile and outcome of acute poisoning among children- a single Centre observational study. J PediatrRes.2016;3(12):875-879.doi:10.17511/ijpr.2016.i12.03. 